\title{
The Pharmaceutical Applications of Next Generation Sequencing in Oncology Drug Designing and Development
}

\section{Dhuha H Nawab*}

Pharmacy College, Umm Al Qura University, Saudi Arabia

\begin{abstract}
Intensive efforts and international collaborations have been performed and are still ongoing in the fight to beat cancer, and many successes have been achieved as a result of hardworking scientists. Although cancer still exists, new information is learned every day, and research continues to be published containing new theories and findings. Cancer research is characterized by the use of advanced technologies that play a role in accelerating results, which then translates into clinical practice to improve the concept of personalized medicine. Currently, next-generation sequencing [NGS] is one of the most advanced technologies used in cancer research due to its ability to provide valuable information from genomic sequencing. Not only is it capable of examining genes but it can also detect and target expected mutations in certain clinical situations and find unexpected sequence variations without consuming substantial time or effort; therefore, NGS provides clinicians with a better understanding of cancer mechanisms. This article demonstrates the pharmaceutical applications of NGS, from tumor markers to pharmacogenomics and targeted therapy, precision medicine, vaccinology, biopharmaceutics, polypharmacology, toxgnostics, and pharmacoepidemiology.
\end{abstract}

Keywords: Next generation sequencing; NGS; Cancer; Pharmacogenomics; Precision medicine; poly pharmacology; Toxgnostics; Pharmacoepidemiology; Personalized biomarker

\section{Introduction}

Genes, which are present in every cell of the body, are composed of deoxyribonucleic acids, or DNA. DNA is composed of the following four nucleotide bases: adenine, guanine, cytosine and thymine [AGCT sequence]. Contrary to popular belief, the DNA sequences of all individuals are $99.9 \%$ identical and only $0.1 \%$ unique.

DNA controls vital cell processes in different ways, such as the control of cell growth, division and death, by making specific proteins; therefore, it is important for each gene to have a specific coding "sequence", allowing all of the subsequent proteins to be made properly. Genetic variations commonly occur, but not all genetic variations cause disease.

Genetic variations are simply differences in DNA sequences, and they can be observed at every genetic level in DNA-in the genes, chromosomes, and proteins and in their functions. Therefore, when discussing the variations in a DNA sequence, one is generally referring to mutations that are present at a level of less than $1 \%$ in a population.

Generally, two types of genetic mutation events create all forms of variation:

1- Single base mutations [single nucleotide polymorphisms, or SNPs] or

\section{2- The insertion or deletion of one or more nucleotides.}

Therefore, if an individual has a mutation (including SNPs, structural variations, copy number variations [CNVs], somatic copy number aberrations [CNAs], insertions, deletions, differentially expressed genes, differentially expressed isoforms, translocations, expressed variations, predicted gene fusions), the presence of these mutations will affect transcription and can alter the protein structure and function, leading to complex diseases, such as cancer.

The beginning of all types of cancer, which is a multifactorial disease that is characterized by its intrinsic heterogeneity [1], begins with mutant cells that create abnormal proteins with altered functions or no protein at all, which then begins the carcinogenic processinitiation, promotion, progression and metastasis. In other words, at the normal cellular scale, there is a balance between growth promoters and inhibitors, but in cancer this balance is lost, leading to sequential processes and the phenotypic hallmarks of malignancy. As proliferation increases, difficulties in differentiation lead to the immortalization of the cells and resistance to normal apoptosis.

The human body normally has the ability to correct the majority of these mutations, but in cancer, this ability differs because the mutations begin to accumulate in vital genes, resulting in alternations to major cellular pathways. As more accumulations occur, the cancer worsens.

Some types of cancer can arise from normal tissues or from specialized cells types, but other types do not fit into the major classifications, such as melanomas, which arise from the neural crest, a primitive embryonic structure [2]. It is worth noting that the information provided by a mutant gene will be different from the normal gene. This clearly shows that there is an increased need to use advanced techniques to read DNA sequences and to detect mutations, to better understand these mutations and to determine the best personalized cure based on the results.

Unfortunately, due to the complexity of cancer, there are currently no drugs that can eliminate cancer cells in patients. Many anticancer therapies are taken in combination and at different cycles, and the majority are toxic, with a narrow therapeutic index and the ability to cause morbidity. The first generation of anticancer therapies began in the 1950s; these therapies were mostly cytotoxic [3] and caused several side effects in cancer patients.

*Corresponding author: Dhuha H Nawab, Pharmacy College, Umm Al Qura University, Saudi Arabia, Tel: +966-12-5270000। 4031; E-mail: Dhuha.nawab@gmail.com

Received April 02, 2015; Accepted May 25, 2015; Published May 29, 2015

Citation: Nawab DH (2015) The Pharmaceutical Applications of Next Generation Sequencing in Oncology Drug Designing and Development. Next Generat Sequenc \& Applic 1: 116. doi:10.4172/2469-9853.1000116

Copyright: @ 2015 Nawab DH. This is an open-access article distributed under the terms of the Creative Commons Attribution License, which permits unrestricted use, distribution, and reproduction in any medium, provided the original author and source are credited. 
Another challenge that lies in cancer treatment is the ability to detect and diagnose cancer during the early stages. The early detection of cancer leads to a significant increase in the cure rate. However, the majority of cancers are detected during their late stages, when treatment opportunities are limited, resulting in poor survival [4]. Therefore, there is a need to utilize more novel approaches for cancer management that allow the targeting of cancer cells without causing harm to normal cells.

The general approaches for cancer management and therapy lie in destroying or removing cancer cells, either via surgery, irradiation, or chemotherapy. The combination of these approaches shows many benefits for improving a cancer patient's quality of life and increasing their survival rate.

Each approach has is important in its own way. Surgery plays multiple roles in cancer management, including prophylaxis if the organ is not crucial for survival; diagnosis, by taking a biopsy from a cancer patient; staging and measuring the extent of the tumor, including allowing the determination of the type of tumor, the growth extent, the size, the nodal involvement and the tumor distance and regional spread; as a definitive or curative treatment, by removing the entire tumor and the lymph nodes that are associated with it; as palliative care to reduce the symptoms and distress; as an adjuvant or supportive therapy, such as a tracheostomy and feeding tubes; as a reconstructive or rehabilitative therapy to reduce deformities; and as a salvage treatment for local disease recurrence, such as via a salvage radical cystectomy or mastectomy [5].

Radiation also plays many roles because both cancer cells and normal cells are affected in cancer. The primary function of radiation is as a curative treatment. For example, some cancer types, such as skin cancer, prostate cancer, early stage larynx cancer and Hodgkin's lymphoma, can only be cured with the use of radiation. Additionally, radiation serves as a form of adjuvant treatment after definitive surgery or as a palliative treatment. This approach has undergone substantial developments, such as the use of intensity-modulated radiation therapy [IMRT], image guided radiotherapy [IGRT], radioimmunotherapy, stereotactic radiosurgery [SRS], and stereotactic radiotherapy [SRT] [5].

Chemotherapies have proven to be effective during the early stages of cancer because they interfere with DNA synthesis steps and tumor replication. They play roles as a form of adjuvant treatment to reduce micrometastases and cancer recurrence or as a neoadjuvant to shrink a tumor [5]. An example is the multi-drug treatment protocol used in Hodgkin's lymphoma. ABVD, which consists of doxorubicin, bleomycin, vinblastine, and dacarbazine, works via intercalation, breaking the DNA strand, and microtubule inhibition [2].

\section{Next-Generation Sequencing [NGS]}

One of the more recent advances in genomic technologies is the development of high-throughput sequencing platforms. These technologies have become powerful tools in cancer research.

High-throughput sequencing is based on 3 main steps: using a solid support to immobilize the DNA samples, using automated fluidic devices for cyclic sequencing reactions and using imaging to detect molecular events [6].

First-generation sequencing [Sanger sequencing] is considered the gold standard for sequencing, has been used as a powerful tool for genomic analysis in the past, and is still in use for the validation of high-throughput sequencing analyses. High-throughput sequencing encompasses all of the terms used to describe a number of sequencing technologies, including Illumina [Solexa] sequencing, Roche 454 sequencing, and SOLiD and Ion Torrent.

NGS is flexible because it can be combined with other technologies and supplementary tests. TAm-seq, which is a method developed by Forshew et al., has the ability to detect TP53 mutations by combining primer design and NGS [7]. NGS has many advantages over Sanger sequencing. For example, during sample preparation, less DNA is required for the preparation of the sequencing libraries; normally $3 \mu \mathrm{g}$ of DNA is required to sequence the BRCA1 and BRCA2 genes using Sanger sequencing, but only 500 ng of DNA is required for chipcaptured NGS sequencing [8].

NGS provides the key to understanding the process of oncogenesis in a genetic manner, due to its ability to provide information regarding a genomic sequence. NGS is capable of both detecting expected mutations in a certain clinical situation and determining unexpected sequence variations, therefore playing a significant role in treatment and in other therapeutic purposes [9].

\section{Applications of NGS}

\section{Tumor markers}

The annual report from the American Cancer Society provides the number of new cancer cases and deaths each year. In 2014, approximately $1,665,540$ new cancer cases were diagnosed, and there were 585,720 cancer deaths. Anyone can develop cancer, but a substantial proportion of cancers can be prevented [10] if diagnosed accurately and early using proper methods and not at the advanced stages of cancer propagation.

What makes cancer so difficult to detect is that the lifespan of most cancers is characterized by silence, which means that all of the changes that occur in normal cells during their conversion into cancer cells, such as dysplasia, hyperplasia and pleomorphism, occur silently [5].

Additionally, a cancer diagnosis can be difficult because the patient may be asymptomatic or have signs and symptoms of other noncancerous diseases; in this case, a diagnostic test is required. Therefore, a biopsy is performed, which requires the surgical removal of a piece of the suspected cancerous region [5].

Currently, a new interest of scientists and researchers is the productions of genome-based blood tests. One of the major benefits of these advanced tests is the detection of tumor markers, which are the materials secreted by a tumor. The development of personalized blood tests for cancer using whole-genome sequencing has been a focus at Johns Hopkins University. Additionally, NeoGenomics, a leading provider of cancer-focused genetic and molecular testing services, announced on Friday, July 11, 2014 that it had launched 23 new types of cancer profiles based on NGS (Figure 1).

The history of the development of tumor markers began during the 1960s when enzymes, hormones and serum proteins were utilized as tumor markers for therapeutic purposes [11].

During the late 1970s, the first tumor marker was discovered, which contained carcinoembryonic antigen [CEA] or carcinoembryonic protein [12], providing new hope and ambition in the fight against cancer by gaining more valuable information regarding the properties of tumor markers and their mechanisms of action. In addition, this discovery provided insights on how to translate this information into clinical practice, especially in cancer patient management.

Tumor markers can be discovered by detecting SNPs, which are the most commonly occurring mutations in the population. Using the 

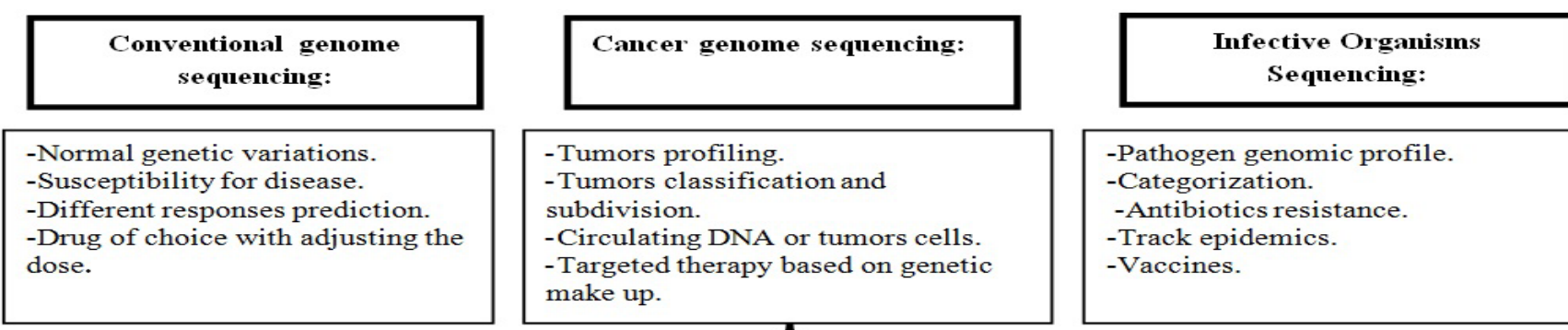

-Pathogen genomic profile.

-Categorization.

-Antibiotics resistance.

-Track epidemics.

-Vaccines.

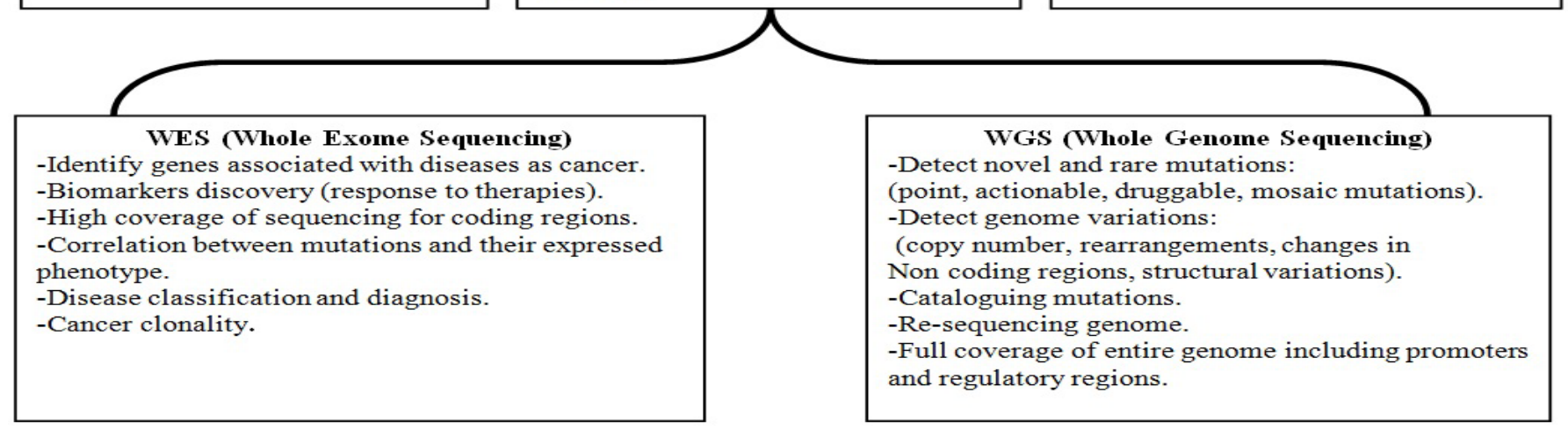

\begin{tabular}{|l|}
\multicolumn{1}{c|}{ Transcriptome Sequencing } \\
-Expression analysis of kind of RNAs classes: \\
(mRNA, microRNA, long coding RNA and \\
non-poly RNA). \\
-RNA editing. \\
-Differential expression. \\
-Splice variants. \\
-Gene fusion. \\
-Gene rearrangement.
\end{tabular}

Epigenetic Sequencing

-Epigenetic profiling (whole genome methylation or methylation of targeted $\mathrm{CpG}$ islands).

- Histone modifications and chromatin remodeling.

-Epigenetic biomarkers.

- Optimal use of epigenetic based drugs (Vorinostat).

- Integration with genomic/transcroptomic analysis.

-Screening.

Figure 1: Clinical applications of NGS

following sequence as an example: ATG CAA to ACG CAA, if a single substitution occurs from $\mathrm{T}$ to $\mathrm{C}$, the entire nucleotide sequence will carry the disease because the change in the sequence, or the mutation that occurred, will produce an abnormal protein. Therefore, this SNP is the marker for this disease.

The next step is the development of strategies for the discovery and utilization of personalized tumor markers by using individual genetic profiles. Thus far, personalized tumor markers have achieved many successes in different fields of oncology, including early cancer detection, screening, diagnosis, prognosis, targeted therapy, therapeutic response, and monitoring and recurrence (Table 1).

\section{Pharmacogenomics [PG]}

Pharmacogenomics is the combination of pharmacology and genomics. This field focuses on the study of how drugs respond differently from person to person due to genomics [13] and how genotype-phenotype information can be utilized in individualized medicine.

The major benefits of PG are as follows:
1. The development of drugs to maximize their therapeutic effects.

2. The ability to design more accurate dosage methods based on an individual's genetic profile rather than using traditional measurements, such as body weight and age [13].

3. The ability to identify the responders /non-responders for different drugs and to determine the risk factors for that drug.

To apply these benefits in real life, one must know the main principles and methodology used in PG, which can be summarized as follows:

1. The use of classical genetics techniques [heritability] by applying Mendelian genetics.

2. The use of genome-wide association studies [GWAS] to examine genetic differences in different individuals, which is performed by comparing the DNA sequences between two groups-the first group is affected by the disease, and the second group is the control without the disease. If the results indicate the presence of a SNP more frequently in one group than in the other, it is likely associated with the disease. 


\begin{tabular}{|c|c|c|}
\hline Cancer type & Tumor marker & Clinical findings \\
\hline \multirow{2}{*}{ Bladder cancer } & ICAM-1/VCAM-1 & Higher in all cancer patients than in controls. \\
\hline & sFas ligand & Higher levels of sFasL predict early recurrence in Ta bladder carcinoma. \\
\hline \multirow{2}{*}{ Brain cancer } & bFGF & Indicate presence of tumor. \\
\hline & VEGF & Indicate presence of tumor. \\
\hline \multirow{2}{*}{ Cervical cancer } & IL-2R & Higher levels in $50 \%$ of patients with squamous cell carcinoma. \\
\hline & SCC & Higher levels in $67.5 \%$ of patients with squamous cell carcinoma. \\
\hline \multirow{2}{*}{ Colon cancer } & Angiogenin & High levels correlated with cancer progression. \\
\hline & E-selectin & Elevated in colon and breast cancer patients. \\
\hline \multirow{2}{*}{ Endometrial cancer } & P53 & Adjunctive test for gynecological cancers preoperative. \\
\hline & IL-2R & Higher levels in $51.4 \%$ of patients with endometrial. \\
\hline \multirow{2}{*}{ Esophagus cancer } & IL-2R & Significantly increased in esophagus cancer patients. \\
\hline & P53 AB & Detected in $43 \%$ of esophagus cancer patients. \\
\hline \multirow{2}{*}{ Stomach cancer } & c-erbB-2 & Correlated with HER-2/neu tissue over expression. \\
\hline & COX-2 & Over expression is associated with high levels of prostaglandin E2 biosynthesis and ogenesis. \\
\hline \multirow{2}{*}{ Breast cancer } & TGF- $\beta$ & Highly expressed in primary breast tumors. \\
\hline & ICAM-1 & High levels in $96 \%$ of sICAM- 1 in breast cancer patients. \\
\hline \multirow{2}{*}{ Leukemia } & TNF- $\alpha$ & Therapy clinical efficacy, indicator of residual disease presence. \\
\hline & IL-2R & Only elevate it in relapse patients, interferon therapy response prediction. \\
\hline \multirow{2}{*}{ Lung cancer } & SVCAM-1 and other CAMs & Detect abnormal levels in SCLC. \\
\hline & TNF- $\alpha$, TGF- $\beta$ & Show favorable prognosis for positive lung cancers. \\
\hline \multirow{2}{*}{ Pancreatic cancer } & $\mathrm{CgA}$ & High levels in $99 \%$ carcinoid tumors .elevated in endocrine pancreatic tumor, multiple endocrine neoplasia 1 syndrome. \\
\hline & P53 mutant protein & Detected in $50 \%$ of the patients. \\
\hline
\end{tabular}

Table 1: The critical roles of tumor markers in different cancer types[11].

3. The use of association studies, which consume significant time and effort, especially during follow-up.

These studies connect phenotypes with genetic markers and are based on three primary strategies:

1. Case-control association studies, 2. family-based association studies, and 3. population-based association studies.

Different drugs have different effects in different populations. This indicates that different patients may have the same symptoms, the same findings, and the same disease, and although they are taking the same drug at the same dose, they show different effects and reactions. Therefore, different people react differently to drugs, which are why they are classified as responders, non-responders, or toxic responders due to these individual variations. A percentage of patients benefit from approved drugs, but a portion of drugs have failed in clinical trials, and more importantly, many approved drugs have been removed from the market due to their serious adverse effects.

Some possible reasons for these individual variations may be ethnicity, age, environment, gender and genetic variation. In the field of drug application, the genetic variations that are present in critical genes that are responsible for metabolizing certain drugs and transporting or targeting drugs will influence a drug's activity (Table 2).

For example, in 5-fluorouracil(5-FU), which uses dihydropyrimidine dehydrogenase [DPYD] as a rate-limiting metabolizing enzyme, the presence of a mutation at DPYD ${ }^{\star} 2 \mathrm{~A}$ will cause partial DPD deficiency, leading to 5-FU toxicity [14-31]. Therefore, other alternatives must be considered, such as changing the drug or changing the dose, depending on the patient's condition. The FDA provides this information on the drug label in the warning section. The Theraguide 5-FU blood test has begun to be used to allow customized management and to minimize the patient's risk for an adverse reaction to 5-FU-related chemotherapies.

In addition, both germline mutations and somatic mutations play roles in drug response. Germline mutations have been used for predicting drug toxicity and efficiency [32] and to develop new or existing therapeutics [33]. Somatic mutations have been used to optimize certain anticancers [32] and to provide accurate drug targets [33]. For example, non-small cell lung cancer sequencing has shown that EGFR tyrosine kinase inhibits sensitivity resistance, which has resulted in the use of routine EGFR sequencing for therapeutic purposes [34].

The application of PG in the drug field begins by targeted identification and discovery, followed by the optimization of a compound, clinical trials, and finally, the launch of a product. Currently, with the huge development in genomic personalized medicine, NGS plays a critical role in designing new therapeutic strategies based on the genetic profile of each individual.

Because cancer is genetically unique, using personalized therapy in cancer is more applicable and should be required. To better understand the concept of designing new therapeutic strategies, DNA sequencing using NGS can detect mutations that will lead to the design of drugs that specifically target these mutations; these drugs are based on genetargeted nucleic acids.

The blocking of apoptosis, cell proliferation, tumor angiogenesis, tumor invasion, tumor suppressor gene dysfunction, increased tumor cell lifespan, DNA synthesis arrest, and drug resistance can all lead to cancer. All of these are carcinogenic effects, the main cause of which is the presence of mutations; therefore, detecting mutant genes will impact the outcome of the therapy (Figure 2).

An example of a target gene involved in proliferation is the Ras oncogene family [K-ras, H-ras, N-ras]. The Rasfamily are proteins involved in transmitting signals within cells from tyrosine kinase receptors to the cell nucleus, and they regulate a wide range of processes [35]. The presence of a mutation will cause the loss of the cell's dephosphorylation ability, leading to an increased proliferation rate and cancer cell survival (Figure 3) [36,37]. 
Citation: Nawab DH (2015) The Pharmaceutical Applications of Next Generation Sequencing in Oncology Drug Designing and Development. Next Generat Sequenc \& Applic 1: 116. doi:10.4172/2469-9853.1000116

\begin{tabular}{|c|c|c|c|}
\hline \multicolumn{4}{|c|}{ Selected Germline Genetic Variants } \\
\hline Drug & $5-\mathrm{FU}$ & 6-MP & Irinotecan \\
\hline Gene & DPD & TPMT & UGT1A1 \\
\hline Role & Rate limiting metabolicenzyme & Major inactivation enzyme & Major enzyme for SN-38Glucuronidation. \\
\hline Mutations & $\begin{array}{l}\text { DPYD*2A= partial DPD } \\
\text { deficiency lead to } 5-F U \\
\text { toxicity[14]. }\end{array}$ & $\begin{array}{l}\text { TPMT }^{*} 2, \mathrm{TPMT}^{\star} 3 \mathrm{~A}, / \mathrm{TPMT}^{*} 3 \mathrm{C}=\text { Low } \\
\text { TMPT activity [3] which may associated } \\
\text { with high myelotoxicity risk [15]. }\end{array}$ & UGT1A1*28=SN-38accumulation leading to Irinotecan toxicity [3]. \\
\hline FDA Label & yes & yes & yes \\
\hline LabelingSection & Warnings & $\begin{array}{l}\text { Dosage and Administration, Contraindic } \\
\text { ations, Precautions, Adverse Reactions, } \\
\text { Clinical Pharmacology }\end{array}$ & $\begin{array}{l}\text { Dosage and Administration, } \\
\text { Warnings, Clinical Pharmacology }\end{array}$ \\
\hline Test & Theraguide $5 \mathrm{FU}$ & TPMT Testing & InvaderR UGT1A1 \\
\hline Url & $\begin{array}{c}\text { http://www.myriad.com/products/ } \\
\text { theraguide-5-fu/ }\end{array}$ & $\begin{array}{c}\text { http://labtestsonline.org/understanding/ } \\
\text { analytes/tpmt/tab/test/ }\end{array}$ & http://www.invaderchemistry.com/invader_applications/invader-ugt1a1.html \\
\hline \multicolumn{4}{|c|}{ Selected Somatic Genetic Variants } \\
\hline Drug & Crizotinib & Vemurafenib & Gefitinib/Erlotinib \\
\hline Gene & EML4-ALK & BRAF V600E & EGFR-tumor activating \\
\hline Role & $\begin{array}{l}\text { receptor tyrosine kinase } \\
\text { that is aberrant in a variety of } \\
\text { malignancies }\end{array}$ & $\begin{array}{l}\text { serine-threonine protein kinases which } \\
\text { involved in many cellular processes. } \\
\text { Mutant BRAF has been implicated in the } \\
\text { pathogenesis of several cancers. }\end{array}$ & $\begin{array}{c}\text { receptor tyrosine kinases, induces a conformational change that } \\
\text { facilitates receptor homo- or heterodimer formation.Activated EGFR } \\
\text { then phosphorylates its substrates, resulting in activation of multiple } \\
\text { downstream pathways within the cell. }\end{array}$ \\
\hline Mutations & $\begin{array}{l}\text {-Resistance in C1156Y, L1196M } \\
\text { mutations present [16-17]. } \\
\text {-Response in EML4-ALK } \\
\text { rearrangement present [18-21]. }\end{array}$ & $\begin{array}{l}\text { - Response in BRAF V600E mutation } \\
\text { present [22].-Resistance in MAPK } \\
\text { pathway reactivation }[23,24]\end{array}$ & $\begin{array}{l}\text {-Response in EGFR-activating mutation present [25-29]. } \\
\text {-Resistance in T790M mutation present }[30,31] .\end{array}$ \\
\hline $\begin{array}{l}\text { FDA Labeling } \\
\text { Section }\end{array}$ & $\begin{array}{l}\text { Indications and Usage, Dosage } \\
\text { and Administration, Drug } \\
\text { Interactions, Warnings and } \\
\text { Precautions, Adverse Reactions, } \\
\text { Clinical Pharmacology, Clinical } \\
\text { Studies }\end{array}$ & $\begin{array}{l}\text { Indications and Usage, Warning and } \\
\text { Precautions, Clinical Pharmacology, } \\
\text { Clinical Studies, Patient Counseling } \\
\text { Information }\end{array}$ & $\begin{array}{l}\text { Indications and Usage, Dosage and } \\
\text { Administration, Clinical } \\
\text { Pharmacology, Clinical Studies }\end{array}$ \\
\hline Test & $\begin{array}{l}\text { theVysis ALK Break ApartFISH } \\
\text { Probe Kit }\end{array}$ & $\begin{array}{l}\text { cobas }[\circledR] 4800 \text { BRAF V600 Mutation } \\
\text { Test }\end{array}$ & cobas $®$ EGFR Mutation Test \\
\hline URL & $\begin{array}{l}\text { http://www.abbottmolecular.co } \\
\text { m/us/products/oncology/fish/lun } \\
\text { g-cancer/vysis-Isi-alk-dual-color- } \\
\text { break-apart-rearrangement- } \\
\text { probe.html }\end{array}$ & $\begin{array}{l}\text { http://molecular.roche.com/assays/Pa } \\
\text { ges/cobas4800BRAFV600MutationT } \\
\text { est.aspx }\end{array}$ & http://molecular.roche.com/assays/Pages/cobasEGFRMutationTest.aspx \\
\hline
\end{tabular}

Table 2: The effect of genetic variations on anticancer drugs and how the FDA uses this information in drug labeling and tests that are approved to detect these mutations.

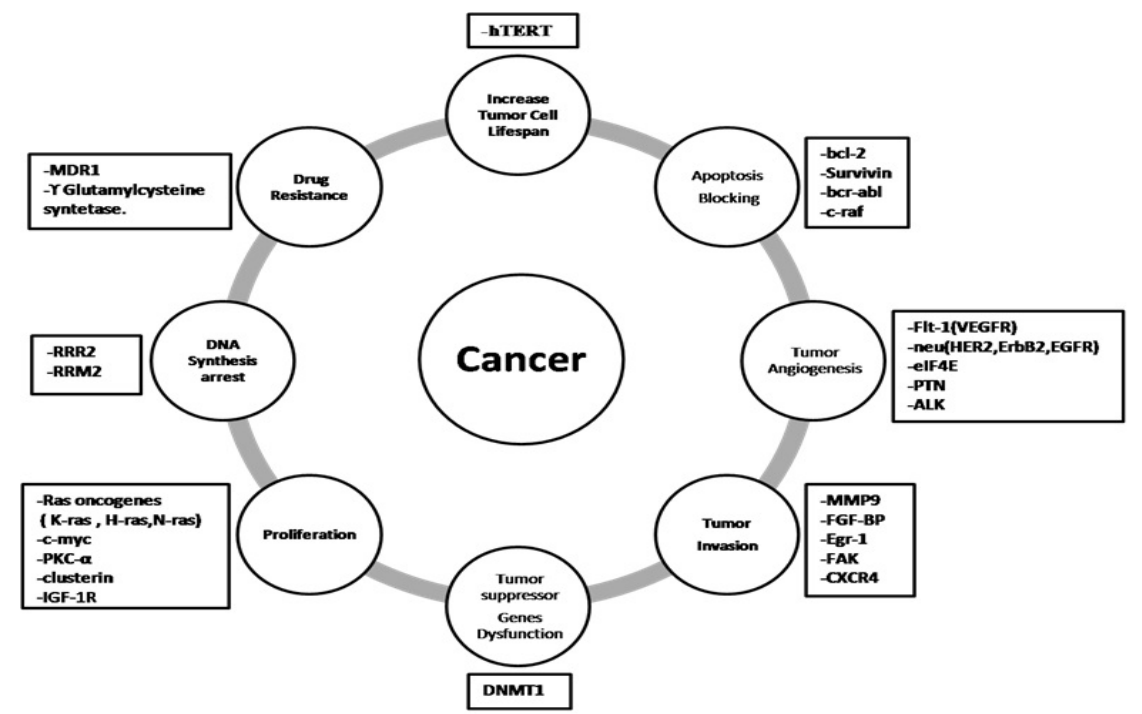

Figure 2: Carcinogenesis Events and Target Genes 
Citation: Nawab DH (2015) The Pharmaceutical Applications of Next Generation Sequencing in Oncology Drug Designing and Development. Next Generat Sequenc \& Applic 1: 116. doi:10.4172/2469-9853.1000116

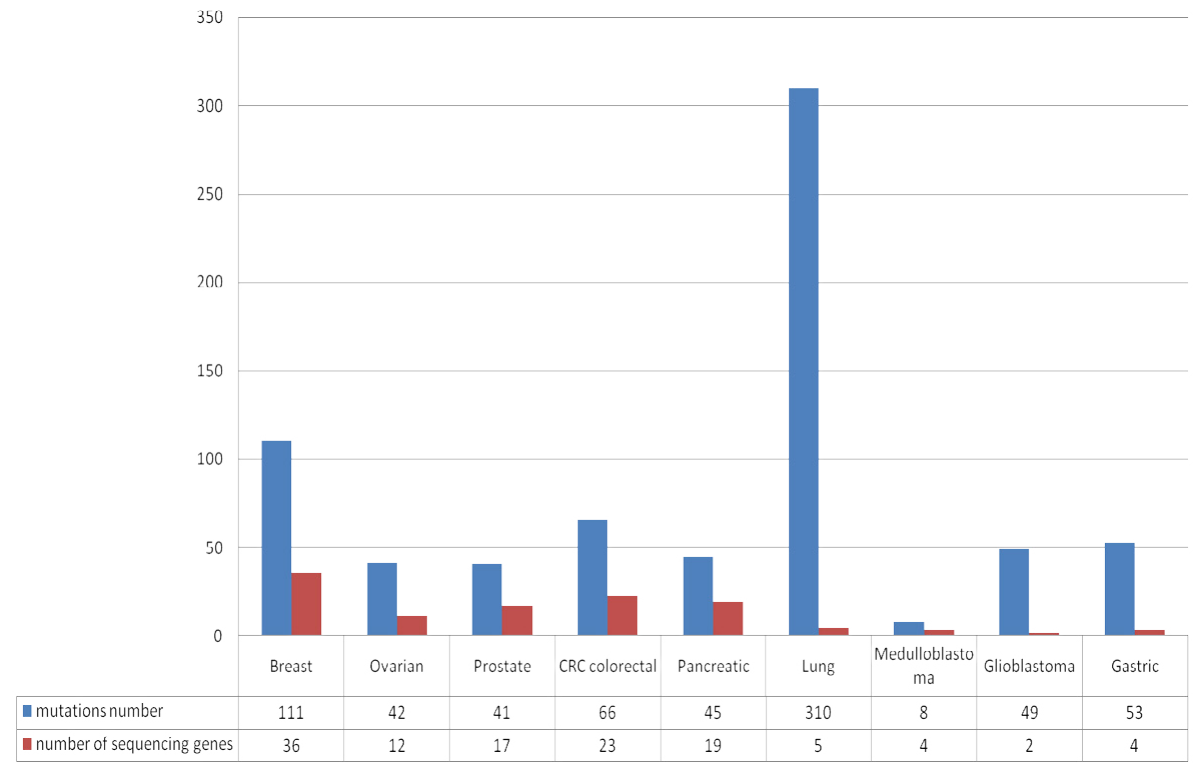

Figure 3: A depiction of the need to apply NGS in cancer showing the number of mutations in different types of cancers and the number of sequenced genes [37].

\begin{tabular}{|c|c|c|c|c|c|c|c|c|c|}
\hline \multirow{6}{*}{\begin{tabular}{|l} 
Cancer Type \\
\\
$\begin{array}{l}\text { Chronic myeloid leukemia } \\
(\mathrm{CML})\end{array}$
\end{tabular}} & \multirow{3}{*}{$\begin{array}{l}\text { Mutation } \\
\text { BCR- } \\
\text { ABL1 } \\
\text { Fusions }\end{array}$} & \multirow{3}{*}{$\begin{array}{l}\text { Type /Location fMutation } \\
\mathrm{t}[9 ; 22][q 34.1 ; \mathrm{q} 11.21] \text { and } \\
\text { other translocations resulting in the } \\
\text { BCR- } \mathrm{BBL} 1 \text { fusion gene }\end{array}$} & \multicolumn{7}{|c|}{ Implications for Targeted Therapeutics } \\
\hline & & & \multirow{2}{*}{\begin{tabular}{|l} 
Imatinib \\
$\begin{array}{l}\text { Confers } \\
\text { sensitivity }\end{array}$
\end{tabular}} & Dasatinib & \multicolumn{2}{|l|}{ Nilotinib } & \multicolumn{2}{|l|}{ Bosutinib } & Ponatinib \\
\hline & & & & $\begin{array}{l}\text { Confers } \\
\text { sensitivity }\end{array}$ & \multicolumn{2}{|l|}{$\begin{array}{l}\text { Confers } \\
\text { Sensitivity }\end{array}$} & \multicolumn{2}{|l|}{$\begin{array}{l}\text { Confers } \\
\text { sensitivity }\end{array}$} & $\begin{array}{l}\text { Confers } \\
\text { sensitivity }\end{array}$ \\
\hline & $\begin{array}{l}\text { BCR- } \\
\text { ABL1 } \\
\text { Y253H }\end{array}$ & $\begin{array}{l}\text { P-loop region of the kinase } \\
\text { domain [Exon 4] }\end{array}$ & $\begin{array}{l}\text { Confers } \\
\text { reduced } \\
\text { sensitivity }\end{array}$ & $\begin{array}{l}\text { Retains } \\
\text { sensitivity }\end{array}$ & \multicolumn{2}{|c|}{$\begin{array}{l}\text { Confers } \\
\text { reduced sensitivity }\end{array}$} & \multicolumn{2}{|c|}{$\begin{array}{l}\text { Unknown } \\
\text { at this time }\end{array}$} & $\begin{array}{l}\text { Unknown } \\
\text { at this time }\end{array}$ \\
\hline & $\begin{array}{l}\text { BCR- } \\
\text { ABL1 } \\
\text { V299L }\end{array}$ & $\begin{array}{l}\text { SH3 contact region of the } \\
\text { BCR-ABL1 kinase domain } \\
\text { [Exon 5] }\end{array}$ & $\begin{array}{l}\text { Confers } \\
\text { reduced } \\
\text { sensitivity }\end{array}$ & $\begin{array}{l}\text { Confers } \\
\text { reduced } \\
\text { sensitivity }\end{array}$ & \multicolumn{2}{|l|}{$\begin{array}{l}\text { Retains } \\
\text { sensitivity }\end{array}$} & \multicolumn{2}{|c|}{$\begin{array}{l}\text { Unknown } \\
\text { at this time }\end{array}$} & $\begin{array}{l}\text { Unknown } \\
\text { at this time }\end{array}$ \\
\hline & $\begin{array}{l}\text { BCR-ABL1 } \\
\text { T315I }\end{array}$ & Kinase domain [Exon 6] & $\begin{array}{l}\text { Confers } \\
\text { reduced } \\
\text { sensitivity }\end{array}$ & $\begin{array}{l}\text { Confers } \\
\text { reduced } \\
\text { sensitivity }\end{array}$ & \multicolumn{2}{|c|}{$\begin{array}{l}\text { Confers reduced } \\
\text { sensitivity }\end{array}$} & \multicolumn{2}{|c|}{$\begin{array}{l}\text { Confers reduced } \\
\text { sensitivity }\end{array}$} & $\begin{array}{l}\text { Retains } \\
\text { sensitivity }\end{array}$ \\
\hline \multirow{2}{*}{$\begin{array}{l}\text { Basal Cell } \\
\text { Carcinoma (BCC) }\end{array}$} & \multirow{2}{*}{$\begin{array}{l}\text { SMO } \\
\text { D473H }\end{array}$} & \multirow{2}{*}{$\begin{array}{l}\text { At the boundary between } \\
\text { the } 6 \text { th transmembrance domain } \\
\text { and an extracellular domain }\end{array}$} & \multicolumn{7}{|l|}{ Vismodegib } \\
\hline & & & \multicolumn{7}{|c|}{ Hypothesized to confer decreased sensitivity } \\
\hline \multirow{5}{*}{$\begin{array}{l}\text { Breast } \\
\text { Cancer }\end{array}$} & \multirow{2}{*}{\multicolumn{2}{|c|}{ AR Expression }} & \multicolumn{3}{|c|}{$\begin{array}{l}\text { Androgen Receptor } \\
\text { Modulators and Antagonists }\end{array}$} & \multicolumn{3}{|c|}{$\begin{array}{l}\text { Estrogen Receptor } \\
\text { Agonists/Antagonists }\end{array}$} & $\begin{array}{l}\text { Aromatase } \\
\text { Inhibitors }\end{array}$ \\
\hline & & & \multicolumn{3}{|c|}{ Confers increased sensitivity } & \multicolumn{3}{|c|}{ Unknown at this time } & $\begin{array}{l}\text { Unknown } \\
\text { at this time }\end{array}$ \\
\hline & \multicolumn{2}{|c|}{ ER Expression } & \multicolumn{3}{|c|}{ Confers increased sensitivity } & \multicolumn{3}{|c|}{$\begin{array}{l}\text { Confers increased } \\
\text { sensitivity }\end{array}$} & $\begin{array}{l}\text { Unknown } \\
\text { at this time }\end{array}$ \\
\hline & \multirow{2}{*}{\multicolumn{2}{|c|}{ HER2 [ERBB2] Amplification }} & Trastuzumab & $\begin{array}{l}\text { Ado- Trastu } \\
\text { Emtansine }\end{array}$ & zumab & Pertuz & & Lapatinib & Neratinib \\
\hline & & & $\begin{array}{l}\text { Confers } \\
\text { increased } \\
\text { sensitivity }\end{array}$ & $\begin{array}{l}\text { Confers } \\
\text { increased s }\end{array}$ & ensitivity & $\begin{array}{l}\text { Confe } \\
\text { increa }\end{array}$ & ensitivity & $\begin{array}{l}\text { Confers } \\
\text { increased } \\
\text { sensitivity }\end{array}$ & $\begin{array}{l}\text { Confers } \\
\text { increased } \\
\text { sensitivity }\end{array}$ \\
\hline \multirow{5}{*}{$\begin{array}{l}\text { Thymic } \\
\text { Malignancies }\end{array}$} & \multirow[b]{2}{*}{ KIT E490K } & \multirow[b]{2}{*}{ Extra-cellular domain [exon 9] } & Imatinib & \multicolumn{2}{|l|}{ Sunitinib } & \multicolumn{2}{|c|}{ Sorafenib } & Dasatinib & \\
\hline & & & $\begin{array}{l}\text { May confer } \\
\text { increased } \\
\text { sensitivity }\end{array}$ & $\begin{array}{l}\text { May confer } \\
\text { sensitivity }\end{array}$ & increased & $\begin{array}{l}\text { May c } \\
\text { sensit }\end{array}$ & increased & $\begin{array}{l}\text { May confe } \\
\text { sensitivity }\end{array}$ & increased \\
\hline & KIT Y553N & Juxtamembrane domain [exon 11] & $\begin{array}{l}\text { Confers } \\
\text { sensitivity }\end{array}$ & $\begin{array}{l}\text { Unknown } \\
\text { at this time }\end{array}$ & & $\begin{array}{l}\text { Unkno } \\
\text { at this }\end{array}$ & & Unknown & it this time \\
\hline & KIT W557R & Juxtamembrane domain [exon 11] & $\begin{array}{l}\text { May confer } \\
\text { increased } \\
\text { sensitivity }\end{array}$ & $\begin{array}{l}\text { May confer } \\
\text { sensitivity }\end{array}$ & increased & $\begin{array}{l}\text { May c } \\
\text { sensit }\end{array}$ & increased & $\begin{array}{l}\text { May confe } \\
\text { sensitivity }\end{array}$ & increased \\
\hline & KIT V560 & Juxtamembrane domain [exon 11] & $\begin{array}{l}\text { Confers } \\
\text { increased } \\
\text { sensitivity }\end{array}$ & $\begin{array}{l}\text { May confer } \\
\text { sensitivity }\end{array}$ & increased & $\begin{array}{l}\text { Unkno } \\
\text { at this }\end{array}$ & & $\begin{array}{l}\text { May confe } \\
\text { sensitivity }\end{array}$ & increased \\
\hline
\end{tabular}


Citation: Nawab DH (2015) The Pharmaceutical Applications of Next Generation Sequencing in Oncology Drug Designing and Development. Next Generat Sequenc \& Applic 1: 116. doi:10.4172/2469-9853.1000116

Page 7 of 12

\begin{tabular}{|c|c|c|c|c|c|c|c|}
\hline & $\begin{array}{l}\text { KIT P577_ } \\
\text { D57 } \\
\text { 9del }\end{array}$ & Juxtamembrane domain [exon 11] & $\begin{array}{l}\text { Unknown } \\
\text { at this time }\end{array}$ & \multicolumn{2}{|c|}{$\begin{array}{l}\text { Unknown } \\
\text { at this time }\end{array}$} & Confers sensitivity & Unknown at this time \\
\hline & KIT D820E & Kinase domain [exon 17] & $\begin{array}{l}\text { May confer } \\
\text { decreased } \\
\text { sensitivity }\end{array}$ & \multicolumn{2}{|c|}{$\begin{array}{l}\text { May confer decreased } \\
\text { sensitivity }\end{array}$} & $\begin{array}{l}\text { Confers increased } \\
\text { sensitivity }\end{array}$ & $\begin{array}{l}\text { May confer increased } \\
\text { sensitivity }\end{array}$ \\
\hline \multirow{8}{*}{$\begin{array}{l}\text { Gastrointestinal } \\
\text { Stromal Tumor } \\
\text { (GIST) }\end{array}$} & \multirow{2}{*}{ BRAF } & \multirow{2}{*}{$\begin{array}{l}\text { V600E mutation substitution at } \\
\text { position } 600 \text { in BRAF } \\
\text { Kinase domain [exon 15] }\end{array}$} & \multicolumn{3}{|c|}{ Imatinib } & \multicolumn{2}{|c|}{ Sunitinib } \\
\hline & & & \multicolumn{3}{|c|}{ Confers resistance } & \multicolumn{2}{|l|}{ Confers resistance } \\
\hline & \multirow{5}{*}{ KIT } & $\begin{array}{l}\text { Extracellular } \\
\text { dimerization motif } \\
\text { [Exon 9] }\end{array}$ & \multicolumn{3}{|c|}{$\begin{array}{l}\text { Confers intermediate sensitivity; } \\
\text { Higher doses of imatinib } \\
\text { [up to } 800 \mathrm{mg} \text { total daily dose] may be } \\
\text { more effective in metastatic disease } \\
\text { than } 400 \mathrm{mg} \text { oral daily }\end{array}$} & \multicolumn{2}{|c|}{ Confers increased sensitivity } \\
\hline & & $\begin{array}{l}\text { Juxtamembrane domain } \\
\text { [Exon 11] }\end{array}$ & \multicolumn{3}{|c|}{ Confers increased sensitivity } & \multicolumn{2}{|c|}{$\begin{array}{l}\text { Decreased sensitivity to second-line sunitinib; } \\
\text { Too few patients have been treated in the } \\
\text { imatinib-naïve setting }\end{array}$} \\
\hline & & $\begin{array}{l}\text { Tyrosine kinase } 1 \text { [TK1] } \\
\text { domain/ATP binding pocket [Exon } \\
\text { 13] }\end{array}$ & \multicolumn{3}{|c|}{$\begin{array}{l}\text { Confers sensitivity as a primary } \\
\text { mutation; } \\
\text { Confers resistance as a secondary } \\
\text { mutation }\end{array}$} & \multicolumn{2}{|c|}{$\begin{array}{l}\text { Sensitive in in vitro studies; } \\
\text { Too few patients in imatinib naïve or second-line } \\
\text { settings to determine }\end{array}$} \\
\hline & & $\begin{array}{l}\text { Tyrosine kinase } 1 \text { [TK1] } \\
\text { domain/ATP binding pocket [Exon } \\
\text { 14] }\end{array}$ & \multicolumn{3}{|c|}{$\begin{array}{l}\text { Confers resistance as a secondary } \\
\text { mutation }\end{array}$} & \multicolumn{2}{|c|}{$\begin{array}{l}\text { Sensitive in vitro studies; } \\
\text { Too few patients in imatinib naïve or second-line } \\
\text { settings to determine }\end{array}$} \\
\hline & & $\begin{array}{l}\text { Tyrosine kinase } 2 \text { [TK2] domain } \\
\text { and activation loop [Exon 17] }\end{array}$ & \multicolumn{3}{|c|}{$\begin{array}{l}\text { Primary mutation sensitive in vitro; } \\
\text { Confers resistance as a secondary } \\
\text { mutation }\end{array}$} & \multicolumn{2}{|c|}{$\begin{array}{l}\text { Confers resistance as secondary mutation; } \\
\text { Too few people treated in imatinib- naïve setting } \\
\text { to determine activity }\end{array}$} \\
\hline & $\begin{array}{l}\text { PDGFRA } \\
\text { D842V }\end{array}$ & $\begin{array}{l}\text { Tyrosine kinase } 2 \text { [TK2] } \\
\text { domain [Exon 18] }\end{array}$ & \multicolumn{3}{|c|}{ Confers decreased sensitivity } & \multicolumn{2}{|c|}{ Confers decreased sensitivity } \\
\hline Bladder Cancer & $\begin{array}{l}\text { TSC1 } \\
\text { E636fs }\end{array}$ & $\begin{array}{l}\text { frameshift introduction of stop } \\
\text { codon into the TSC1 gene [Exon 15] }\end{array}$ & \multicolumn{5}{|c|}{$\begin{array}{l}\text { mTOR inhibitors: } \\
\text { Confers increased sensitivity }\end{array}$} \\
\hline $\begin{array}{l}\text { Inflammatory } \\
\text { myofibroblastic } \\
\text { tumor (IMT) }\end{array}$ & $\begin{array}{l}\text { ALK } \\
\text { Fusions }\end{array}$ & $\begin{array}{l}\text { Chromosomal rearrangements } \\
\text { involving the ALK gene on } 2 \mathrm{p} 23\end{array}$ & \multicolumn{5}{|c|}{$\begin{array}{l}\text { ALK inhibitors: } \\
\text { Confers increased sensitivity }\end{array}$} \\
\hline Gastric Cancer & HER2 & HER2 amplification & \multicolumn{5}{|c|}{ Trastuzumab: Confers increased sensitivity } \\
\hline \multirow{7}{*}{$\begin{array}{l}\text { Non-Small Cell } \\
\text { Lung Cancer } \\
\text { (NSCLC) }\end{array}$} & \multirow{2}{*}{$\begin{array}{l}\text { ALK } \\
\text { Fusions }\end{array}$} & \multirow{2}{*}{$\begin{array}{l}\text { Chromosomal rearrangements } \\
\text { involving } \\
\text { the ALK gene on } 2 \mathrm{p} 23\end{array}$} & \multicolumn{2}{|l|}{ ALK TKIs } & HSP90 inhibitors & \multicolumn{2}{|l|}{ EGFR TKIs } \\
\hline & & & \multicolumn{2}{|c|}{$\begin{array}{l}\text { Confers increased } \\
\text { sensitivity }\end{array}$} & $\begin{array}{l}\text { Confers increased } \\
\text { sensitivity }\end{array}$ & \multicolumn{2}{|c|}{ Confers decreased sensitivity } \\
\hline & & Kinase domain [exon 19] Insertion & \multicolumn{2}{|l|}{$\begin{array}{l}\text { Unknown } \\
\text { at this time }\end{array}$} & $\begin{array}{l}\text { Unknown at this } \\
\text { time }\end{array}$ & \multicolumn{2}{|c|}{ Confer s increased sensitivity } \\
\hline & EGFR & $\begin{array}{l}\text { Kinase domain [exon 19] } \\
\text { DELETION }\end{array}$ & $\begin{array}{l}\text { Unknown at } \\
\text { time }\end{array}$ & this & $\begin{array}{l}\text { Unknown at this } \\
\text { time }\end{array}$ & Confers increased & tivity \\
\hline & & Kinase domain [exon 20] Insertion & Unknown at th & is time & Unknown at this time & Confers decrease & itivity \\
\hline & ROS1 & Chromosomal rearrangements & & Crizo & inib & rlotinib/Gefitinib & \\
\hline & Fusions & involving the ROS1 gene on $6 q 22$ & Confers incr & eased & ensitivity & onfers decreased $\mathrm{s}$ & ity \\
\hline
\end{tabular}

Table 3: Examining the effect of mutations in more detail by looking at the locations of mutations in different types of cancers and the effects of different anticancer drugs. *data has been taken from mycancergenome.com

When using breast cancer as an example, upon comparing the number of mutations (111 mutations) with the number of sequenced genes (36 genes), the results show that there is an absolute need to detect all of the mutations and to use the given information to find the best tools and methods in diagnosis and treatment (Table 3).

For example, in chronic myelogenous leukemia [CML], which is a type of cancer that affects humans, the presence of BCR-ABL1 fusions at the location $\mathrm{t}[9 ; 22]$ [q34.1;q11.21] confers sensitivity to 5 anticancer drugs, whereas the presence of the BCR-ABL1 Y253H mutation in the P-loop region of the kinase domain [exon 4] confers reduced sensitivity to imatinib and nilotinib but retains sensitivity to dasatinib. The effects of ponatinib and bosutinib are unknown. Additional studies and clinical trials are still required to understand their effects.

\section{Targeted cancer therapy}

Above, we describe how mutations in genes will affect the outcome of therapy and move the science of drug design forward. In cancer research, the development of drugs that target carcinogenesis events is called targeted cancer therapy or rational drug design. The primary goal of these targeted drugs is to interfere with specific molecules involved in cancer without causing any harm to normal cells. Targeted drugs are the cornerstone of precision medicine and the current focus of anticancer discovery and development [38]. 
Standard chemotherapy works in a non-selective manner because it acts on all rapidly dividing cells, whether they are cancerous or normal, but targeted cancer therapies are designed and synthesized to be delivered to and only react with their target; therefore, they act on specific molecular targets that are associated with cancer. In cytogenetics, targeted therapies are cytostatic [they block tumor cell proliferation], whereas standard chemotherapy agents are cytotoxic [they kill tumor cells] [38].

With the recent advances in genetic medicine and the sequencing of the human genome, the concept of a "druggable genome" has become more applicable and popular [39-41]. A number of approaches are used to identify potential targets, and it is always possible to discover new approaches. One approach is to compare the amount of proteins present in cancer cells with the amount of proteins present in normal cells. An example of a differentially expressed target is the human epidermal growth factor receptor 2 protein [HER-2], which is expressed at high levels in some cancer cells.

Several targeted therapies are directed against HER-2, including trastuzumab [Herceptin ${ }^{\otimes}$ [ [38]. In addition, non-small cell lung cancer sequencing has shown the presence of EGFR tyrosine kinase inhibitor sensitivity resistance, which has resulted in the use of routine EGFR sequencing for therapeutic purposes [34]. Recently, a study was published online (23 September 2014) that discussed the use of Mir-34 as a new weapon against cancer [42].

Another approach is to determine whether cancer cells produce mutant [altered] proteins that drive cancer progression. For example, BRAF, which is a cell growth signaling protein, has been found to be present in an altered form [BRAF V600E] in many melanomas. The current approved drug is vemurafenib [Zelboraf ${ }^{\bowtie}$ ], and it targets the mutant form of the BRAF protein to treat patients with this type of cancer (Table 4) [38].

The primary methods of targeted cancer therapy include hormone therapies, signal transduction inhibitors, gene expression modulators, apoptosis inducers, angiogenesis inhibitors, immunotherapies, and toxin delivery molecules [38]. Hormone therapies, which are used to treat tumors that are sensitive to hormones, such as breast cancer, uterine cancer and prostate cancer, work by reducing the hormones that stimulate tumor growth or by blocking the hormone receptor. For example, aromatase inhibitors, such as anastrozole, block the formation of estrogen, tamoxifen citrate blocks antiestrogens, bicalutamide blocks androgen receptor antagonists, and abarelix [antagonist] and gosrelin [analog] block GnRH analogs and its antagonists [43].

Kinase inhibitors, which are a new group of anticancers known as signal transduction inhibitors, target the cellular mechanisms of signal transduction and block the activity of molecules that play a role in or participate in these mechanisms. Examples include imatinib, which was the first agent in this group and works as a BCR-ABL kinase inhibitor; dasatinib, which is a multikinase inhibitor; everolimus, which is an mTOR inhibitor; and gefitinib, which is an EGFR tyrosine kinase inhibitor [43].

Gene expression modulators modify the functions of proteins that play a role in controlling gene expression. For example, triplex-forming oligonucleotides [TFO] bind to the major groove of duplex DNA, leading to the creation of a third strand or a triple helix [44,45].

Apoptosis inducers are also used because cancer cells avoid apoptosis. Therefore, the mechanism of action of this group is strategies that result in the death of cancer cells [38].

Angiogenesis inhibitors block the nourishment of the tumor by blocking the growth of new blood vessels or by targeting the molecules responsible for stimulating the growth of new blood vessels. For example, itraconazole inhibits VEGFR phosphorylation [46,47].

Monoclonal antibodies, which are designed to target the proteins expressed in tumor cells, make the cancer cell more visible to the immune system. For example, rituximab, which targets CD20, blocks growth signals; cetuximab, which targets EGFR, stops new blood vessels from forming; bevacizumab, which targets VEGFR, delivers radiation to cancer cells; and ibritumomabtiuxetan, which is labeled with yttrium 90, blocks CD20 [43].

\begin{tabular}{|c|c|c|}
\hline FDA-Approved Indication[S] & Target[S] & Targeted Drugs \\
\hline Colorectal cancer [KRAS wild type] & EGFR [HER1/ERBB1] & Panitumumab [Vectibix] \\
\hline Renal cell carcinoma & VEGFR, PDGFR, KIT & Pazopanib [Votrient] \\
\hline Melanoma & PD-1 & Pembrolizumab [Keytruda] \\
\hline Breast cancer [HER2+] & HER2 [ERBB2/neu] & Pertuzumab [Perjeta] \\
\hline $\begin{array}{l}\text { Chronic myelogenous leukemia Acute lymphoblastic } \\
\text { leukemia [Philadelphia chromosome positive] }\end{array}$ & ABL, FGFR1-3, FLT3, VEGFR2 & Ponatinib [Iclusig] \\
\hline $\begin{array}{l}\text { Gastric cancer or Gastroesophageal } \\
\text { junction [GEJ] adenocarcinoma }\end{array}$ & VEGFR2 & Ramucirumab[Cyramza] \\
\hline Colorectal cancer Gastrointestinal stromal tumors & KIT, PDGFR $\beta$, RAF, RET, VEGFR1/2/3 & Regorafenib[Stivarga] \\
\hline $\begin{array}{c}\text { Non-Hodgkin's lymphoma Chronic lymphocytic } \\
\text { leukemia Rheumatoid arthritis Granulomatosis with } \\
\text { polyangiitis }\end{array}$ & CD20 & Rituximab [Rituxan, Mabthera] \\
\hline $\begin{array}{l}\text { Cutaneous T-cell lymphoma Peripheral T-cell } \\
\text { lymphoma }\end{array}$ & HDAC & Romidepsin[Istodax] \\
\hline Myelofibrosis & JAK1/2 & Ruxolitinib[Jakafi] \\
\hline MulticentricCastleman's disease & IL-6 & Siltuximab[Sylvant] \\
\hline $\begin{array}{c}\text { Hepatocellular carcinoma Renal cell carcinoma } \\
\text { Thyroid carcinoma }\end{array}$ & VEGFR, PDGFR, KIT, RAF & Sorafenib[Nexavar] \\
\hline Renal cell carcinoma & mTOR & Temsirolimus[Torisel] \\
\hline Rheumatoid arthritis Juvenile idiopathic arthritis & IL-6R & Tocilizumab[Actemra] \\
\hline Rheumatoid arthritis & JAK3 & Tofacitinib[Xeljanz] \\
\hline Non-Hodgkin's lymphoma & CD20 & Tositumomab[Bexxar] \\
\hline
\end{tabular}




\begin{tabular}{|c|c|c|}
\hline Melanoma [with BRAF V600 mutation] & MEK & Trametinib[Mekinist] \\
\hline $\begin{array}{c}\text { Breast cancer [HER2+] } \\
\text { Gastric cancer [HER2+] }\end{array}$ & HER2 [ERBB2/neu] & Trastuzumab[Herceptin] \\
\hline Medullary thyroid cancer & EGFR [HER1/ERBB1], RET, VEGFR2 & Vandetanib[Caprelsa] \\
\hline Melanoma [with BRAF V600 mutation] & BRAF & Vemurafenib[Zelboraf] \\
\hline Basal cell carcinoma & PTCH, Smoothened & Vismodegib[Erivedge] \\
\hline Cutaneous T-cell lymphoma & HDAC & Vorinostat[Zolinza] \\
\hline Colorectal cancer & PIGF, VEGFA/B & Ziv-aflibercept[Zaltrap] \\
\hline
\end{tabular}

Table 4: Targeted therapies that have been approved by the FDA.

\section{Precision medicine}

Personalized medicine, genomic medicine, stratified medicine, and targeted medicine are concepts that focus on characterizing individual biological profiles by analyzing the genome and using the results to guide medical decisions to provide patients with the best health care. Precision medicine is generally defined as providing the right patient with the right drug at the right time by precisely targeting the molecular pathways that caused the disease. Precision medicine links the multifactorial characteristics of each individual. A unique feature of precision medicine is that it does not depend only on genomic medicine; it also incorporates a patient's lifestyle, non-genomic biological information, environmental parameters and other relevant data [1].

NGS, which has paved the way for precision medicine, has gained many successes in the field of oncology, allowing each individual to have a comprehensive genomic profile. This provides many advantages for the cancer patient. For example, it allows the generation of specific tumor data based on the patient's characteristics, which can then be used later for targeted therapy, genome-based blood tests, biomarkers and other clinical applications.

Roy Chowdhury's report was the first study to apply NGS in personalized oncology. He showed that using such techniques not only improved patient health care but also made the best use of the existing available genetic information. The aim of the study was to discover the practical challenges of using NGS in the field of clinical oncology. The researchers implemented whole-genome sequencing [WGS], targeted whole-exome sequencing [WES] [the coding regions of the genome] of both normal and cancer DNA, and transcriptome sequencing [RNAseq] [transcribed RNAs] for each patient [48].

The results detected many mutation categories [gene expression alterations, structural rearrangements, point mutations, copy number alternations], and the findings were discussed by a multidisciplinary sequencing tumor board [STB], which included a panel of a wide range of specialists, including those working in clinical oncology, cancer genetics, bioinformatics, clinical pathology, social and behavioral sciences and bioethics [49].

Two patients were enrolled in the pilot study, one with melanoma and the other with colorectal cancer, and both were treated unsuccessfully. After determining the final results of their sequencing and taking a deep look into their genetic profiles, the melanoma patient was shown to have HRAS, a CDKN2C structural rearrangement. The sequencing tumor board [STB] suggested using PI3K and MEK inhibitors as a treatment for the patient. Sequencing results in the colorectal cancer patient detected CDK8, an NRAS variation that may be used as a future therapeutic target [48].

Additionally, one of the most successful cases of the use of NGS in clinical practice is an inspiring study that was performed at Washington
University and was headed by genetics researchers who performed transcriptome sequencing and whole-genome sequencing [WGS] for a researcher on the team affected by adult acute lymphoblastic leukemia [ALL]. The results showed that the FLT3 gene was highly active in the leukemia cells. The anticancer drug sunitinib, which is approved by the FDA to treat gastrointestinal stromal tumors, renal cell carcinoma, and pancreatic cancer, inhibits FLT3. After using sunitinib, the patient's blood returned to normal (Table 5) [50-60].

\section{Biopharmaceutics}

One of the major classes of anticancer agents are monoclonal antibodies, which bind to a target and activate the host's immune mechanisms, leading to the killing of the cancer cells by either complete mediated lysis or via killer cells. Monoclonal antibodies can attach to an inactive growth factor receptor on a cancer cell, thus inhibiting survival pathways and promoting apoptosis. Cetuximab is a monoclonal antibody directed against EGFR, erbitux is a well-known anti-EGFR antibody, rituximab lyses $\mathrm{B}$ lymphocytes by binding to the calcium channel forming CD20, and trastuzumab binds to HER2.

The importance of NGS in this field lies in generating an antibody library because NGS data can provide a more precise analysis of multiplicity in an antibody library [61]. In addition, NGS can be used in interactome profiling to detect protein interactions with multifunctional enzymes [62], thus providing new potential methods for studying protein-protein interactions and antibody-antigen binding [61].

\section{Polypharmacology}

The philosophy of drug design has been converted to the idea of one drug multiple targets rather one drug one target [63-68]. Polypharmacology is still a major challenge in drug development. This technique includes using a single drug that is capable of affecting multiple targets in a specific disease pathway or using a single drug that affects multiple targets connected to multiple disease pathways [69]. Polypharmacology aims to explore drug repurposing, which includes exploring the unidentified off targets of available drugs [70-72]. In regards to anticancers, polypharmacology is considered a primary treatment approach because anticancers are often taken in combination with MOPP, a curative combination prototype that consists of nitrogen mustard, vincristine [Oncovin], procarbazine and prednisone.

The importance of NGS lies in using this approach for targeting, to increase a drug's efficacy and minimize its toxicity. Additionally, NGS can detect a wide variety of rare, actionable mutations that can be used as targets, and polypharmacology aims to find multitargets; therefore, they are complementary to each other.

NGS provides multitargets, and polypharmacology delivers the drug. In addition, NGS can be used for ligand-based predictions, target-based predictions, and phenotype-based predictions [including 
Citation: Nawab DH (2015) The Pharmaceutical Applications of Next Generation Sequencing in Oncology Drug Designing and Development. Next Generat Sequenc \& Applic 1: 116. doi:10.4172/2469-9853.1000116

Page 10 of 12

\begin{tabular}{|c|c|c|c|}
\hline Cancer Type & Sample & Major Findings & Findings Importance \\
\hline \multicolumn{4}{|c|}{ Whole Genome sequencing (WGS) } \\
\hline Melanoma & WGS:25 & $\begin{array}{l}\text { Detect : } \\
\text { - Mutated gene, PREX2.-Comprehensive sequencing of } \\
\text { human melanoma tumors. }\end{array}$ & $\begin{array}{l}\text { PREX2 mutations are biologically related, ectopic } \\
\text { expression of mutant PREX } 2 \text { accelerated tumor } \\
\text { formation of immortalized human melanocytes in } \\
\text { vivo [52]. }\end{array}$ \\
\hline Breast cancer & $\begin{array}{l}\text { WES : } 103 \\
\text { WGS: } 22\end{array}$ & $\begin{array}{l}\text { Detect: } \\
\text { - Repeated mutation in CBFB.-Deletion of RUNX1. } \\
\text {-Repeated MAGI3-AKT3 fusion. }\end{array}$ & $\begin{array}{l}\text { MAGI3-AKT3fusion led to AKT kinase activation } \\
\text { which cancelled by ATP-competitive AKT small } \\
\text { molecular inhibitor treatment [53]. }\end{array}$ \\
\hline \multicolumn{4}{|c|}{ Whole exome sequencing (WES) } \\
\hline Uterine serous carcinoma & WES:10 & $\begin{array}{l}\text { Detect : Somatic mutation in TP53, PIK3CA, FBXW7, } \\
\text { PPP2R1A. }\end{array}$ & $\begin{array}{l}\text { Cyclin E- FBXW7, PI3K, TP53 have a role in the } \\
\text { etiology of uterine serous carcinoma [54]. }\end{array}$ \\
\hline $\begin{array}{l}\text { Head and neck squamous } \\
\text { cancer }\end{array}$ & WES:32 & Detect :- Mutation in FBXW7, NOTCH1. & $\begin{array}{l}40 \% \text { of } 28 \text { identified mutations in NOTCH1 were } \\
\text { truncate gene product. } \\
\text { - NOTCH1 may function as tumor suppressor [55]. }\end{array}$ \\
\hline \multicolumn{4}{|c|}{ Transcriptomic sequencing } \\
\hline Colon cancer & $\begin{array}{l}\text { WGS: } 2 \\
\text { WES:72 } \\
\text { RNA-seq: } 68\end{array}$ & $\begin{array}{l}\text { Detect :- IGF2 over expression. } \\
\text { - Repeated gene fusion RSPO2,RSPO3 }\end{array}$ & $\begin{array}{l}\text {-RSPO may have a role in Wnt signaling activation } \\
\text { and tumerigenesis . } \\
\text {-R spondin gene fusion provide new therapeutic } \\
\text { opportunities [56]. }\end{array}$ \\
\hline $\begin{array}{l}\text { thyroid cancer cells } \\
\text { [TPC-1] and leukemia cells }\end{array}$ & MicroRNAs:90 & $\begin{array}{l}\text { Defined region upstream of a conserved } \\
\text { GXGXXG kinase motif. }\end{array}$ & $\begin{array}{l}\text { * Tyrosine kinase [TK] fusions are attractive drug } \\
\text { targets in cancers } \\
\text { * identified for the first time the genomic fusion } \\
\text { sequences of CCDC6-RET in TPC-1 cells and } \\
\text { FGFR1OP2-FGFR1 in KG-1 cells [57]. }\end{array}$ \\
\hline \multicolumn{4}{|c|}{ Targeted sequencing } \\
\hline familial breast cancer & $N=12$ & $\begin{array}{l}\text {-Identified all } 19 \text { distinct BRCA1 and } 35 \text { distinct BRCA2 } \\
\text { sequence alterations. } \\
\text { *Detection of BRCA1, BRCA2 variants from introns and } \\
\text { untranslated regions. }\end{array}$ & $\begin{array}{l}\text { Individuals and families carrying } \\
\text { mutations in BRCA1 and BRCA2 [BRCA1/2] have } \\
\text { a markedly elevated risk of developing breast and } \\
\text { ovarian cancers [58]. }\end{array}$ \\
\hline Prostate cancer & $N=45$ & $\begin{array}{l}-182 \text { cancer associated genes. } \\
-37 \text { introns of commonly rearranged genes. } \\
\text {-Novel and actionable BRAF rearranged. }\end{array}$ & $\begin{array}{l}\text { Designing targeted assays to detect } \\
\text { driving mutations, drug targets, future therapies, } \\
\text { biomarkers [59]. }\end{array}$ \\
\hline \multicolumn{4}{|c|}{ Epigenetic sequencing } \\
\hline Bladder cancer & $N=212$ & $\begin{array}{l}\text { - 1,627 hypermethylated promoter targets in the BC cell. } \\
\text { - VAX1, LMX1A are associated with BC recurrence. } \\
\text { - VAX1, KCNV1, TAL1, PPOX1, and CFTR } \\
\text { are associated with BC diagnosis. }\end{array}$ & $\begin{array}{l}\text { Identified a promising diagnostic marker panel for } \\
\text { early non-invasive detection and subsequent BC } \\
\text { surveillance [60]. }\end{array}$ \\
\hline $\begin{array}{l}\text { Non-small cell lung } \\
\text { Cancer }\end{array}$ & $N=48$ & $\begin{array}{l}\text { - Identified } 57 \text { differentially methylated regions [DMRs] } \\
\text { present in all NSCLC tumors. } \\
\text { - Hypermethylated DMRs were strongly associated with } \\
\text { genes encoding transcriptional regulators. } \\
\text { - Subtelomeric regions and satellite repeats were } \\
\text { hypomethylated in the NSCLC samples. } \\
\text { - Identified DMRs that were specific to adenocarcinomas } \\
\text { and squamous cell carcinomas. }\end{array}$ & $\begin{array}{l}\text { Provide a resource containing } \\
\text { genome-wide DNA methylation maps of NSCLC } \\
\text { and their paired lung tissues, and comprehensive } \\
\text { lists of known and novel DMRs and } \\
\text { associated genes in NSCLC [61]. }\end{array}$ \\
\hline
\end{tabular}

Table 5: Studies showing the remarkable success of using NGS in precision medicine

transcriptomic-based methods, proteomics-based approaches, and drug target identification [73].

\section{Toxgnostics}

Most anticancers are toxic and cause severe side effects, such as cisplatin, which causes nephrotoxicity and ototoxicity; temozolomide, which causes genotoxicity, fetotoxicity, and teratogenicity; and 6-mercaptopurine, which is dose-dependent and causes hepatotoxicity. These side effects have led to the field of toxgnostics in cancer medicine. Toxgnostics, which is generally defined as a systemic study, focuses on studying genetic toxicity predictors that are related to and caused by anticancers [74].

NGS revolutionized our ability to predict anticancer toxicity, determine the causes of toxicity and detect toxgnostic variants. NGS can also predict the toxicity level in each patient based on the genetic profile and the number of people who may be responsive to a specific drug. Toxgnostics aims to find the relationship between a plasma drug concentration profile and the toxicity level and to create a personalized treatment plan for each patient, which may require elective dose adjustment for a select drug [74].

\section{Vaccinology}

NGS can be utilized in the initial development stages 3 of a vaccine to evaluate its efficiency and safety [75]. Due to the accuracy of NGS and its ability to detect sequence variants in each individual, NGS can provide more reasons and solutions to help understand why some people may face side effects after receiving vaccines, but others may not [61]. 
Citation: Nawab DH (2015) The Pharmaceutical Applications of Next Generation Sequencing in Oncology Drug Designing and Development. Next Generat Sequenc \& Applic 1: 116. doi:10.4172/2469-9853.1000116

\section{Pharmacoepidemiology}

Pharmacoepidemiology, which uses variations in study designs to determine the effects of drug treatments on populations and clinical situations [76]. NGS has been successfully used in this field because epigenetics plays a role in tumorigenesis and paves the way for drug discovery. The two important mechanisms of epigenetics are DNA methylation and histone modification. For example, epigenetics can be used for the following:

-epigenetic-based biomarkers [for colorectal cancer, septin 9 is used to block methylation] [77].

-epigenetic-based drugs [for treatment of cutaneous T-cell lymphoma, vorinostat, a histone deacetylase inhibitor from Merck, is used $[78,79]$.

\section{Conclusion}

Next-generation sequencing has proven to be the cornerstone of advanced research. This includes not only cancer research but also all areas of human genetics. By improving the speed and precision of the results, designing new therapeutic strategies can be achieved to improve the outcome of cancer treatments and save as many lives as possible.

\section{References}

1. Servant N, Roméjon J, Gestraud P, La Rosa P, Lucotte G, et al. (2014) Bioinformatics for precision medicine in oncology: principles and application to the SHIVA clinical trial. Front Genet 5: 152.

2. Weinberg RA (2013) The Biology of Cancer. (2ndedn).

3. Neidle S (2013) Cancer Drug Design and Discovery. Elsevier Inc.

4. Wu W, Choudhry H (2013) Next Generation Sequencing in Cancer Research. Springer.

5. Gates RA, Regina MF (2008) Oncology Nursing Secrets. (3rdedn).

6. Ezpeleta NR, Hackenberg M, Aransay AM (2012) Bioinformatics for High Throughput Sequencing.

7. Ozretia L, Heukamp LC, Odenthal M, Buettner R (2012) The role of molecular diagnostics in cancer diagnosis and treatment. Onkologie 35 Suppl 1: 8-12.

8. Guan YF, Li GR, Wang RJ, Yi YT, Yang L, et al. (2012) Application of nextgeneration sequencing in clinical oncology to advance personalized treatment of cancer. Chin J Cancer 31: 463-470.

9. Cronin M, Ross JS (2011) Comprehensive next-generation cancer genome sequencing in the era of targeted therapy and personalized oncology. Biomark Med 5: 293-305.

10. http://www.cancer.org/treatment/understandingyourdiagnosis/ examsandtestdescriptions/tumormarkers/\#

11. Wu JT (2002) Circulating Tumor Markers of the New Millennium: Target Therapy, Early Detection, and Prognosis, Clinical chemistry. (1stedn), Amer Assn for Clinical Chemistry.

12. Wu JT (1999) Review of circulating tumor markers: from enzyme carcinoembryonic protein to oncogene and suppressor gene. Ann Clin Lab Sci 29: 106-111.

13. Nishant T, Bindu HK, Kumar SD, Kumar AR (2012) PharmacogenomicsPersonalized Treatment of Cancer, Diabetes and Cardiovascular Diseases. J Pharmacogenom Pharmacoproteomics 3: 107.

14. Lee A, Ezzeldin H, Fourie J, Diasio R (2004) Dihydropyrimidine dehydrogenase deficiency: impact of pharmacogenetics on 5-fluorouracil therapy. Clinical advances in hematology \&oncology: $\mathrm{H} \& \mathrm{O} 2:$ 527-532.

15. Dancey JE, Bedard PL, Onetto N, Hudson TJ (2012) The genetic basis for cancer treatment decisions. Cell 148: 409-420.

16. Choi YL, Soda M, Yamashita Y, Ueno T, Takashima J, et al. (2010) EML4-ALK mutations in lung cancer that confer resistance to ALK inhibitors. N Engl J Med 363: $1734-1739$
17. Sasaki T, Okuda K, Zheng W, Butrynski J, Capelletti M, et al. (2010) The neuroblastoma-associated F1174L ALK mutation causes resistance to an ALK kinase inhibitor in ALK-translocated cancers. Cancer Res 70: 10038-10043.

18. Inamura K, Takeuchi K, Togashi Y, Hatano S, Ninomiya H, et al. (2009) EML4ALK lung cancers are characterized by rare other mutations, a TTF-1 cell lineage, an acinar histology, and young onset. Mod Pathol 22: 508-515.

19. Koivunen JP, Mermel C, Zejnullahu K, Murphy C, Lifshits E, et al. (2008) EML4ALK fusion gene and efficacy of an ALK kinase inhibitor in lung cancer. Clin Cancer Res 14: 4275-4283.

20. Shaw AT, Yeap BY, Mino-Kenudson M, Digumarthy SR, Costa DB, et al. (2009) Clinical features and outcome of patients with non-small-cell lung cancer who harbor EML4-ALK. J Clin Oncol 27: 4247-4253.

21. Soda M, Takada S, Takeuchi K, Choi YL, Enomoto M, et al. (2008) A mouse model for EML4-ALK-positive lung cancer. Proc Natl Acad Sci U S A 105 : 19893-19897.

22. Flaherty KT, Puzanov I, Kim KB, Ribas A, McArthur GA, et al. (2010) Inhibition of mutated, activated BRAF in metastatic melanoma. N Engl J Med 363: 809819

23. Johannessen CM, Boehm JS, Kim SY, Thomas SR, Wardwell L, et al. (2010) COT drives resistance to RAF inhibition through MAP kinase pathway reactivation. Nature 468: 968-972.

24. Nazarian R, Shi H, Wang Q, Kong X, Koya RC, et al. (2010) Melanomas acquire resistance to $\mathrm{B}-\mathrm{RAF}(\mathrm{V} 600 \mathrm{E})$ inhibition by RTK or N-RAS upregulation. Nature 468: 973-977.

25. Pao W, Miller V, Zakowski M, Doherty J, Politi K, et al. (2004) EGF receptor gene mutations are common in lung cancers from "never smokers" and are associated with sensitivity of tumors to gefitinib and erlotinib. Proc Natl Acad Sci USA 101: 13306-13311

26. Paez JG, Jänne PA, Lee JC, Tracy S, Greulich H, et al. (2004) EGFR mutations in lung cancer: correlation with clinical response to gefitinib therapy. Science 304: 1497-1500.

27. Lynch TJ, Bell DW, Sordella R, Gurubhagavatula S, Okimoto RA, et al. (2004) Activating mutations in the epidermal growth factor receptor underlying responsiveness of non-small-cell lung cancer to gefitinib. N Engl J Med 350: 2129-2139.

28. Riely GJ, Politi KA, Miller VA, Pao W (2006) Update on epidermal growth factor receptor mutations in non-small cell lung cancer. Clin Cancer Res 12: 7232 7241.

29. Toschi L, Cappuzzo F (2007) Understanding the new genetics of responsiveness to epidermal growth factor receptor tyrosine kinase inhibitors. Oncologist 12 : 211-220.

30. Pao W, Miller VA, Politi KA, Riely GJ, Somwar R, et al. (2005) Acquired resistance of lung adenocarcinomas to gefitinib or erlotinib is associated with a second mutation in the EGFR kinase domain. PLoS Med 2: e73.

31. Yun $\mathrm{CH}$, Mengwasser KE, Toms AV, Woo MS, Greulich $\mathrm{H}$, et al. (2008) The T790M mutation in EGFR kinase causes drug resistance by increasing the affinity for ATP. Proc Natl Acad Sci U S A 105: 2070-2075.

32. Weng L, Zhang L, Peng Y, Huang RS (2013) Pharmacogenetics and pharmacogenomics: a bridge to individualized cancer therapy Pharmacogenomics 14: 315-324.

33. Smith SA, French T, Hollingsworth SJ (2014) The impact of germline mutations on targeted therapy. J Pathol 232: 230-243.

34. McLeod HL (2013) Cancer pharmacogenomics: early promise, but concerted effort needed. Science 339: 1563-1566.

35. Barbacid M (1987) ras genes. Annu Rev Biochem 56: 779-827.

36. Campbell SL, Khosravi-Far R, Rossman KL, Clark GJ, Der CJ (1998) Increasing complexity of Ras signaling. Oncogene 17: 1395-1413.

37. Vogelstein B, Papadopoulos N, Velculescu VE, Zhou S, Diaz LA Jr, et al. (2013) Cancer genome landscapes. Science 339: 1546-1558.

38. http://www.cancer.gov/cancertopics/treatment/types/targeted-therapies/ targeted-therapies-fact-sheet

39. Patel MN, Halling-Brown MD, Tym JE, Workman P, Al-Lazikani B (2013) Objective assessment of cancer genes for drug discovery. Nat Rev Drug Discov 12: 35-50. 
Citation: Nawab DH (2015) The Pharmaceutical Applications of Next Generation Sequencing in Oncology Drug Designing and Development. Next Generat Sequenc \& Applic 1: 116. doi:10.4172/2469-9853.1000116

40. Hopkins AL, Groom CR (2002) The druggable genome. Nat Rev Drug Discov 1: 727-730.

41. Overington JP, Al-Lazikani B, Hopkins AL (2006) How many drug targets are there? Nat Rev Drug Discov 5: 993-996.

42. Misso G, Di Martino MT, De Rosa G, Farooqi AA, Lombardi A, et al. (2014) Mir34: a new weapon against cancer? Mol Ther Nucleic Acids 3: e194.

43. Cohen V (2012) Basic Concepts in Pharmacology: What You Need to Know for Each Drug Class, 4th Edition. Ann Pharmacother.

44. Sargent RG, Kim S, Gruenert DC (2011) Oligo/polynucleotide-based gene modification: strategies and therapeutic potential. Oligonucleotides 21: 55-75.

45. Uil TG, Haisma HJ, Rots MG (2003) Therapeutic modulation of endogenous gene function by agents with designed DNA-sequence specificities. Nucleic Acids Res 31: 6064-6078.

46. Aftab BT, Dobromilskaya I, Liu JO, Rudin CM (2011) Itraconazole inhibits angiogenesis and tumor growth in non-small cell lung cancer. Cancer Res 71: 6764-6772.

47. Chong CR, Xu J, Lu J, Bhat S, Sullivan DJ Jr, et al. (2007) Inhibition of angiogenesis by the antifungal drug itraconazole. ACS Chem Biol 2: 263-270.

48. Roychowdhury S, lyer MK, Robinson DR, Lonigro RJ, Wu YM, et al. (2011) Personalized oncology through integrative high-throughput sequencing: a pilot study. Sci Transl Med 3: 111ra121.

49. Corless CL (2011) Medicine. Personalized cancer diagnostics. Science 334 1217-1218.

50. http://pharmaceuticalintelligence.com/2012/07/09/sunitinib-brings-adult-all-toremission-rna-sequencing/

51. Berger MF, Hodis E, Heffernan TP, Deribe YL, Lawrence MS, et al. (2012) Melanoma genome sequencing reveals frequent PREX2 mutations. Nature 485: 502-506.

52. Banerji S, Cibulskis K, Rangel-Escareno C, Brown KK, Carter SL, et al. (2012) Sequence analysis of mutations and translocations across breast cancer subtypes. Nature 486: 405-409.

53. Kuhn E, Wu RC, Guan B, Wu G, Zhang J, et al. (2012) Identification of molecular pathway aberrations in uterine serous carcinoma by genome-wide analyses. J Natl Cancer Inst 104: 1503-1513.

54. Agrawal N, Frederick MJ, Pickering CR, Bettegowda C, Chang K, et al. (2011) Exome sequencing of head and neck squamous cell carcinoma reveals inactivating mutations in NOTCH1. Science 333: 1154-1157.

55. Seshagiri S, Stawiski EW, Durinck S, Modrusan Z, Storm EE, et al. (2012) Recurrent R-spondin fusions in colon cancer. Nature 488: 660-664.

56. Chmielecki J, Peifer M, Jia P, Socci ND, Hutchinson K, et al. (2010) Targeted next-generation sequencing of DNA regions proximal to a conserved GXGXXG signaling motif enables systematic discovery of tyrosine kinase fusions in cancer. Nucleic Acids Res 38: 6985-6996.

57. Ozcelik H, Shi X, Chang MC, Tram E, Vlasschaert M, et al. (2012) Long-range PCR and next-generation sequencing of BRCA1 and BRCA2 in breast cancer. J Mol Diagn 14: 467-475.

58. Beltran H, Yelensky R, Frampton GM, Park K, Downing SR, et al. (2013) Targeted next-generation sequencing of advanced prostate cancer identifies potential therapeutic targets and disease heterogeneity. Eur Urol 63: 920-926.

59. Zhao Y, Guo S, Sun J, Huang Z, Zhu T, et al. (2012) Methylcap-seq reveals novel DNA methylation markers for the diagnosis and recurrence prediction of bladder cancer in a Chinese population. PLoS One 7: e35175.
60. Carvalho RH, Haberle V, Hou J, van Gent T, Thongjuea S, et al (2012) Genome-wide DNA methylation profiling of non-small cell lung carcinomas. Epigenetics Chromatin 5: 9.

61. Woollard PM, Mehta NA, Vamathevan JJ, Van Horn S, Bonde BK, et al. (2011) The application of next-generation sequencing technologies to drug discovery and development. Drug Discov Today 16: 512-519.

62. Di Niro R, Sulic AM, Mignone F, D'Angelo S, Bordoni R, et al. (2010) Rapid interactome profiling by massive sequencing. Nucleic Acids Res 38: e110.

63. Hopkins AL (2008) Network pharmacology: the next paradigm in drug discovery Nat Chem Biol 4: 682-690.

64. Hopkins AL (2009) Drug discovery: Predicting promiscuity. Nature 462: 167 168.

65. Apsel B, Blair JA, Gonzalez B, Nazif TM, Feldman ME, et al. (2008) Targeted polypharmacology: discovery of dual inhibitors of tyrosine and phosphoinositide kinases. Nat Chem Biol 4: 691-699.

66. Simon Z, Peragovics A, Vigh-Smeller M, Csukly G, Tombor L, et al. (2012) Drug effect prediction by polypharmacology-based interaction profiling. J Chem Inf Model 52: 134-145.

67. Brianso F, Carrascosa MC, Oprea TI, Mestres J (2011) Cross-pharmacology analysis of $G$ protein-coupled receptors. Curr Top Med Chem 11: 1956-1963.

68. Paolini GV, Shapland RH, van Hoorn WP, Mason JS, Hopkins AL (2006) Globa mapping of pharmacological space. Nat Biotechnol 24: 805-815.

69. Reddy AS, Zhang S (2013) Polypharmacology: drug discovery for the future Expert Rev Clin Pharmacol 6: 41-47.

70. Oprea TI, Mestres J (2012) Drug repurposing: far beyond new targets for old drugs. AAPS J 14: 759-763.

71. Oprea TI, Nielsen SK, Ursu O, Yang JJ, Taboureau O, et al. (2011) Associating Drugs, Targets and Clinical Outcomes into an Integrated Network Affords a New Platform for Computer-Aided Drug Repurposing. Mol Inform 30: 100-111.

72. Achenbach J, Tiikkainen P, Franke L, Proschak E (2011) Computational tools for polypharmacology and repurposing. Future Med Chem 3: 961-968.

73. Tang J, Aittokallio T (2014) Network pharmacology strategies toward multitarget anticancer therapies: from computational models to experimental design principles. Curr Pharm Des 20: 23-36

74. Church D, Kerr R, Domingo E, Rosmarin D, Palles C, et al. (2014) 'Toxgnostics': an unmet need in cancer medicine. Nat Rev Cancer 14: 440-445.

75. Victoria JG, Wang C, Jones MS, Jaing C, McLoughlin K, et al. (2010) Vira nucleic acids in live-attenuated vaccines: detection of minority variants and an adventitious virus. J Virol 84: 6033-6040.

76. Freedman AN, Sansbury LB, Figg WD, Potosky AL, Weiss Smith SR, et al. (2010) Cancer pharmacogenomics and pharmacoepidemiology: setting a research agenda to accelerate translation. J Natl Cancer Inst 102: 1698-1705.

77. Grützmann R, Molnar B, Pilarsky C, Habermann JK, Schlag PM, et al. (2008) Sensitive detection of colorectal cancer in peripheral blood by septin 9 DNA methylation assay. PLoS One 3: e3759.

78. Delmore JE, Issa GC, Lemieux ME, Rahl PB, Shi J, et al. (2011) BET bromodomain inhibition as a therapeutic strategy to target c-Myc. Cell 146: 904-917.

79. Kaiser J (2010) Epigenetic drugs take on cancer. Science 330: 576-578. 